\title{
Controlled Chemistry Helium High Temperature Materials Test Loop
}

\author{
Richard N. Wright
}

August 2005

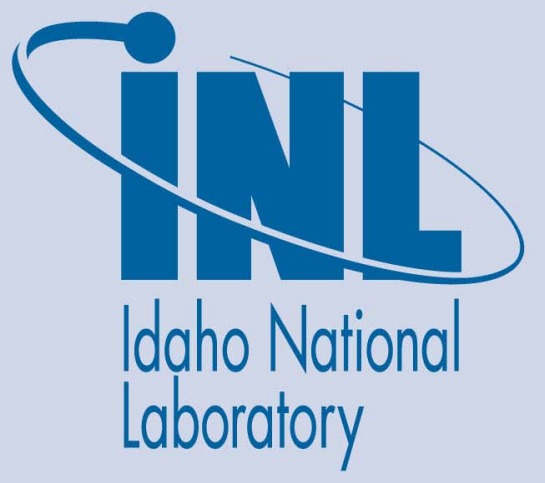

The INL is a U.S. Department of Energy National Laboratory operated by Battelle Energy Alliance 
INL/EXT-05-00653

\section{Controlled Chemistry Helium High Temperature Materials Test Loop}

Richard N. Wright

August 2005

\section{Idaho National Laboratory \\ Idaho Falls, Idaho 83415}

Prepared for the

U.S. Department of Energy

Office of Nuclear Energy

Under DOE Idaho Operations Office

Contract DE-AC07-05ID14517 


\section{SUMMARY}

A system to test aging and environmental effects in flowing helium with impurity content representative of the Next Generation Nuclear Plant (NGNP) has been designed and assembled. The system will be used to expose microstructure analysis coupons and mechanical test specimens for up to 5,000 hours in helium containing potentially oxidizing or carburizing impurities controlled to parts per million levels. Impurity levels in the flowing helium are controlled through a feedback mechanism based on gas chromatography measurements of the gas chemistry at the inlet and exit from a high temperature retort containing the test materials. Initial testing will focus on determining the nature and extent of combined aging and environmental effects on microstructure and elevated temperature mechanical properties of alloys proposed for structural applications in the NGNP, including Inconel 617 and Haynes 230. 


\section{ACKNOWLEDGMENTS}

The author gratefully acknowledges the contributions of W. D. Swank and D. C. Haggard in design and assembly of the helium flow loop. A. K. Wertsching contributed significantly to developing methods to predict corrosion behavior of Inconel 617 in NGNP atmospheres. The continued support and technical advice from D. F. Wilson on elevated temperature environmental testing and specification of system components is also gratefully acknowledged. 


\section{CONTENTS}

Introduction.

Design and Assembly of a Controlled Chemistry Low Flow Test Loop....................................... 8

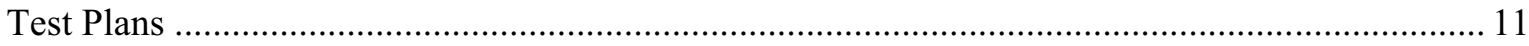

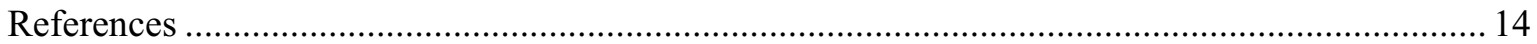

\section{FIGURES}

Figure 1. Schematic representation of the NGNP reactor and power conversion vessel and associated thermo-chemical hydrogen generation plants........................................................................ 5

Figure 2. Schematic diagram illustrating the relationship of the gas chemistry (described by the partial pressure of oxygen and carbon activity) with the expected behavior of Inconel 617 at elevated temperature.

Figure 3. Calculated stability diagrams for Inconel 617 for the nominal NGNP impure He environment. The red square indicates the behavior of the alloy with respect to the gas chemistry at 850 and $1000^{\circ} \mathrm{C}$

Figure 4. Schematic of the INL low velocity controlled chemistry helium materials test system.

Figure 5. Details of the retort for exposure of test coupons.

Figure 6. Photograph illustrating the seven sapphire seated needle valves used to introduce very precise amounts of impurity and the attached rotary valves (shown as green in the photo).

Figure 7. Photograph of the assembled low velocity controlled chemistry test loop. The computer shown controls the measurement of gas chemistry using the mass spectrometer; a second computer that is not shown controls automation of the gas chemistry through operation of the valves shown in Figure 6.

\section{TABLES}

Table I. Compositions of impure He environments used in previous testing. 5

Table II. Compositions of potential high temperature alloys for NGNP; compositions in Weight \%......... 7 


\section{INTRODUCTION}

Requirements for long term microstructure stability and superior creep resistance suggest that the solid solution nickel based alloys Inconel 617 or Haynes 230 are leading candidates for structural applications in the NGNP. This reactor will likely use helium coolant, experience with previous high temperature gas cooled reactor designs indicates that the helium will contain significant amounts of impurities during operation. One of the critical technical issues is long term performance of alloys at high temperature in this environment.

Either of the proposed alloys will likely perform well in oxidizing environments due to the formation of a tenacious protective chrome oxide. The large amount of graphite in proposed NGNP designs raises the possibility that the helium environment may have insufficient oxygen partial pressure to sustain the chrome oxide and carburization or decarburization of the alloys may occur. An experimental program to systematically investigate the influence of the possible range of NGNP impure helium chemistries on microstructure and mechanical properties of candidate materials has been developed. As part of that work a controlled chemistry materials test loop has been designed and assembled. This report describes the salient features of this test loop and outlines the experimental evaluations that will be performed to validate the performance of alloys for the high temperature reactor environment.

\section{Background}

The Next Generation Nuclear Plant (NGNP) is being developed to produce hydrogen as well as electricity. Conceptual designs call for a gas cooled reactor with an outlet temperature greater than $850^{\circ} \mathrm{C}$ required to efficiently operate the hydrogen generation plant. While the design concepts are not yet final, it is highly probable that helium will be the working fluid in the reactor. The primary material in the core will be graphite and the prime candidates for metallic internal components are the nickel based alloys Inconel 617 or Alloy 230. An artist's representation of the reactor and power conversion vessel and the associated hydrogen generation plants is shown in Figure 1 below. A heat exchanger in the power conversion vessel (shown in orange in the figure) will take approximately $10 \%$ of the thermal energy of the reactor and divert it as process heat to the hydrogen production plant. 


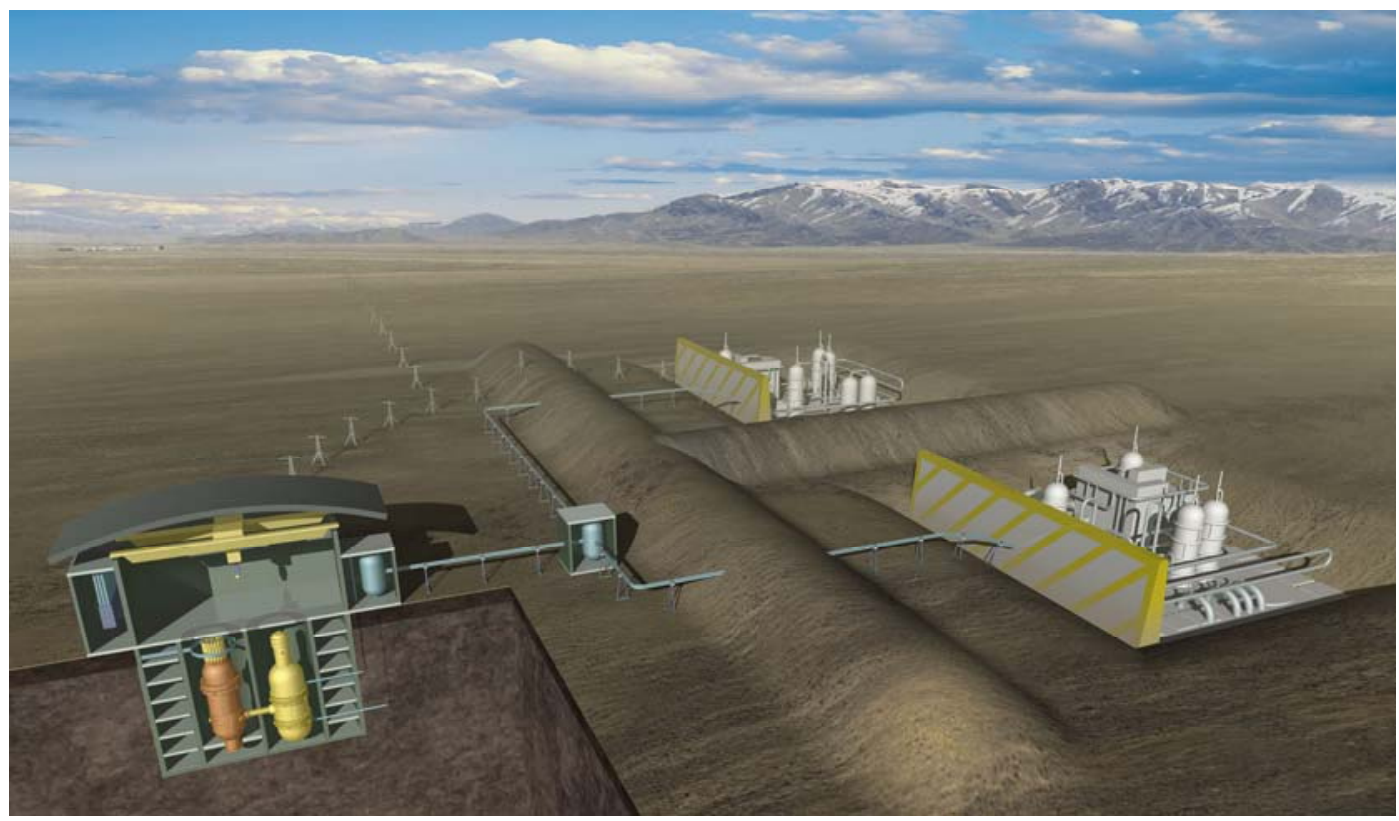

Figure 1. Schematic representation of the NGNP reactor and power conversion vessel and associated thermo-chemical hydrogen generation plants.

Experience with similar high temperature gas cooled reactors has shown that helium on the primary side of the reactor will have significant levels of impurities during reactor operation. The expected composition range for impurities in the NGNP has been examined and is shown in Table I, along with values used previously for a number of reactor programs. [1] Impurities in the helium arise from a number of sources including impurities in the graphite, lubricants in pumps and valves, and leakage into the system. Note that results of measurements from the gas cooled Fort Saint Varain plant in the United States are not included in Table I since there were substantial leaks of steam into primary circuit from the power generation circuit in this plant. The NGNP is envisioned to operate with a direct power generation cycle and steam ingress cannot occur.

\begin{tabular}{|c|c|c|c|c|c|c|c|}
\hline Program & $\begin{array}{c}\mathbf{H}_{2} \\
(\mu \mathrm{atm})\end{array}$ & $\begin{array}{c}\mathrm{H}_{2} \mathrm{O} \\
(\mu \mathrm{atm})\end{array}$ & $\underset{(\mu \mathrm{atm})}{\mathrm{CO}}$ & 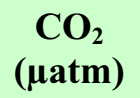 & 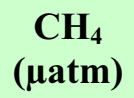 & $\mathbf{N}_{2}$ ( $\mu$ atm) & $\begin{array}{c}\text { He (atm } \\
\text { absolute) }\end{array}$ \\
\hline HHT & 500 & 1.5 & 40 & & 50 & $5-10$ & 2 \\
\hline PNP & 500 & 1.5 & 15 & & 20 & $<5$ & 2 \\
\hline AGCNR & 400 & 2 & 40 & 0.2 & 20 & $<10$ & 2 \\
\hline
\end{tabular}

Table I. Compositions of impure He environments used in previous testing. [1] 
HHT - High Temperature Helium Turbine Systems

PNP - Prototype Nuclear Process Heat

AGCNR - Advanced Gas Cooled Nuclear Reactor

It has been determined that the values for the impurities determined for the AGCNR program are the appropriate nominal levels for the NGNP program. The gas compositions in Table I are not in thermodynamic equilibrium, rather they represent a kinetic steady state. The actual gas chemistry at a point within the reactor will be determined by reaction rates between the impurity species and are a strong function of temperature. [1-4] Impurity content is influenced by reaction of materials with the coolant, for example oxidation of metallic components will deplete the gas stream of oxygen. Methane $\left(\mathrm{CH}_{4}\right)$ is produced in the core by a radiolytic reaction between graphite and water vapor and will decompose to carbon and hydrogen at high temperature in the absence of radiolysis.

Reactions which can occur and are thought to be quite rapid include:

$2 \mathrm{C}+\mathrm{O}_{2} \leftrightarrow 2 \mathrm{CO}$

$\mathrm{C}+\mathrm{H}_{2} \mathrm{O} \leftrightarrow \mathrm{CO}+\mathrm{H}_{2}$

$\mathrm{C}+\mathrm{CO}_{2} \leftrightarrow 2 \mathrm{CO}$

Other possible reactions, that are thought to proceed more slowly include:

$\mathrm{CO}+\mathrm{H}_{2} \mathrm{O} \leftrightarrow \mathrm{H}_{2}+\mathrm{CO}$

$\mathrm{C}+2 \mathrm{H}_{2} \leftrightarrow \mathrm{CH}_{4}$

In addition to the balance between these competing reactions, gas cooled reactors have also employed gas purification systems of several different types and with varying capacity. The gas chemistry is thus a complex balance that will vary depending on how the system is operated and as a function of temperature within the plant. With respect to interaction with materials, either graphite or metallics, the potential for oxidation or carburization is the critical concern. The oxidation potential of the gas is determined by the partial pressure ratio $\mathrm{H}_{2} / \mathrm{H}_{2} \mathrm{O}$ and the carburization potential is related to the ratios $\mathrm{CH}_{4} / \mathrm{H}_{2}$ and $\mathrm{CO} / \mathrm{CO}_{2}$.

The most critical metallic component in the NGNP system is the heat exchanger used to provide process heat to the hydrogen generation plant. This heat exchanger is expected to be of a compact design located within the power conversion vessel and will operate at the reactor outlet temperature. The reactor system is intended to have a license period of 60 years. The combination of very high temperature operation and long duration of service restricts material choices for the heat exchanger to a small number of coarse grained solid solution strengthened high nickel alloys for stability and creep resistance, and that have high chromium content for environmental resistance. [5-8] Compositions of these candidate alloys are given in Table II. Based on creep resistance above $850^{\circ} \mathrm{C}$, the leading candidate alloys are Inconel 617 and Haynes 230. 


\begin{tabular}{|c|c|c|c|c|c|c|c|c|c|c|c|}
\hline Alloy & Ni & Fe & $\mathbf{C r}$ & $\mathbf{C o}$ & $\mathbf{M o}$ & $\mathbf{A l}$ & $\mathbf{W}$ & $\mathbf{T i}$ & $\mathbf{C}$ & $\mathbf{S i}$ & $\mathbf{M n}$ \\
\hline $\begin{array}{c}\text { Inconel } \\
617\end{array}$ & 44.5 & 3 & $\begin{array}{c}20- \\
24\end{array}$ & $\begin{array}{c}10- \\
15\end{array}$ & $\begin{array}{c}8- \\
10\end{array}$ & $\begin{array}{c}0.8- \\
1.5\end{array}$ & & 0.6 & $\begin{array}{c}0.05- \\
0.15\end{array}$ & 1 & 1 \\
\hline $\begin{array}{c}\text { Alloy } \\
230\end{array}$ & Bal & 3 & $\begin{array}{c}20- \\
24\end{array}$ & 5 & $1-3$ & $\begin{array}{c}0.2- \\
0.5\end{array}$ & $\begin{array}{c}13- \\
15\end{array}$ & & $\begin{array}{c}0.05- \\
0.15\end{array}$ & $\begin{array}{c}.25- \\
.75\end{array}$ & $0.3-1$ \\
\hline $\begin{array}{c}\text { Alloy } \\
800 \mathrm{H}\end{array}$ & $30-$ & 35 & $\begin{array}{c}19-5 \\
23\end{array}$ & & $\begin{array}{c}0.15- \\
0.6\end{array}$ & $\begin{array}{c}0.15- \\
0.6\end{array}$ & $\begin{array}{c}0.05- \\
0.1\end{array}$ & & \\
\hline $\begin{array}{c}\text { Alloy } \\
\text { XR }\end{array}$ & Bal & 20 & 23 & 1 & 10 & 0.1 & 1 & 0.03 & 0.15 & 0.5 & 1 \\
\hline
\end{tabular}

Table II. Compositions of potential high temperature alloys for NGNP; compositions in Weight \%. [5-8]

The reaction of Inconel 617 with the expected range of helium impurity contents for the NGNP can be shown schematically in a stability diagram of the type shown schematically in the Figure 2. [2] This plot reflects the potential for the gas to be either oxidizing or carburizing with respect to the thermodynamic stability of chromium in the alloy as an oxide, carbide or the metallic species. The line $\mathrm{P}^{*}$ co represents a critical CO content where there is equilibrium between the phases.

Behavior of the alloy is described by a location on the diagram in five distinct regions denoted by the roman numerals. For atmospheres in regions IV and V, chrome carbide is the stable phase and the alloy will be carburized; however, in region IV some non-protective chromium oxide can be formed. In regions I and II rapid decarburization of the alloy will occur. Region III represents the most stable atmosphere for the alloy. In this region there may be some potential for carburization, however, there is sufficient oxygen partial pressure for a protective oxide to form and prevent substantial penetration of carbon into the alloy.

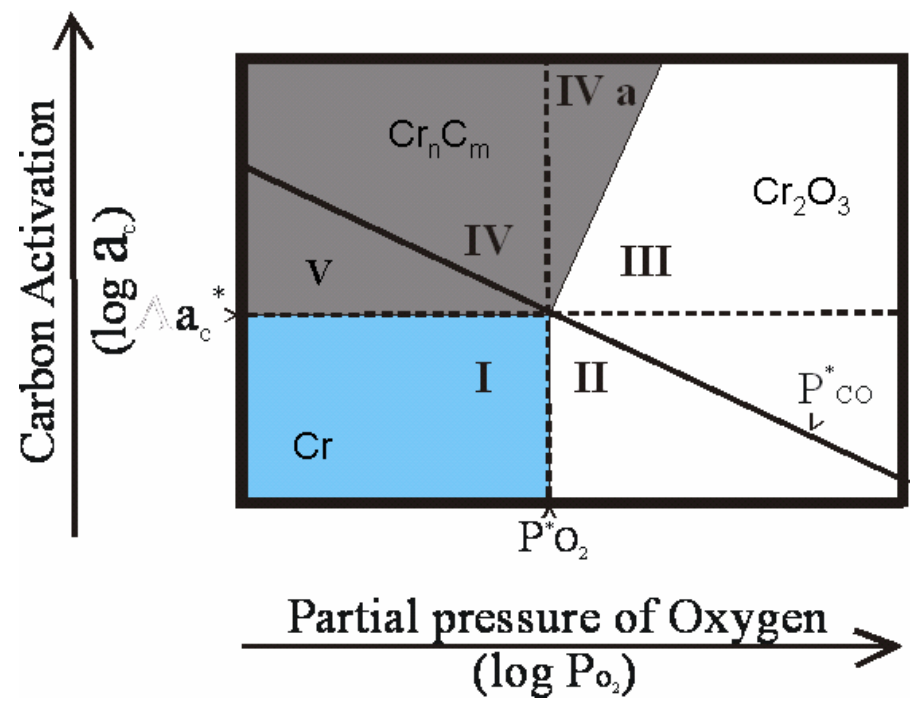



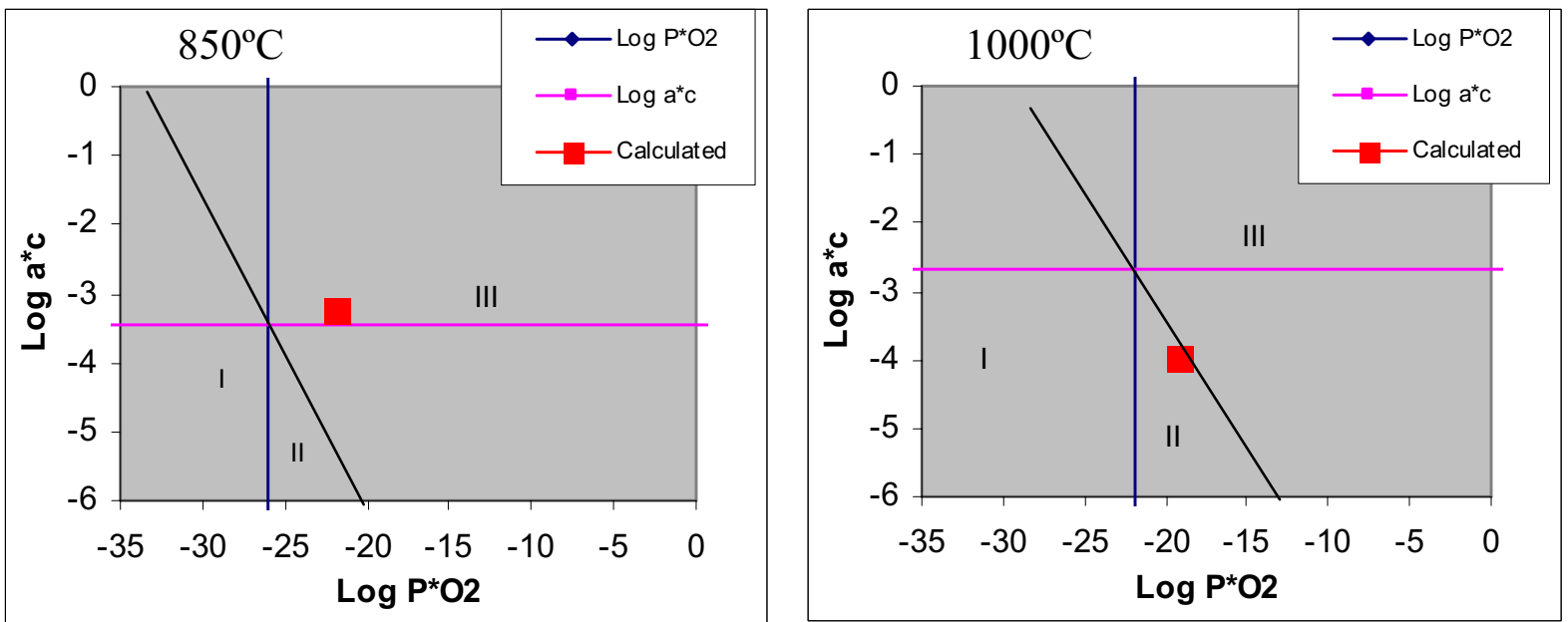

Figure 2. Schematic diagram illustrating the relationship of the gas chemistry (described by the partial pressure of oxygen and carbon activity) with the expected behavior of Inconel 617 at elevated temperature.

Figure 3. Calculated stability diagrams for Inconel 617 for the nominal NGNP impure He environment. The red square indicates the behavior of the alloy with respect to the gas chemistry at 850 and $1000^{\circ} \mathrm{C}$.

The gas chemistry and the interaction between the gas and the alloy are in a dynamic steady state, rather than an equilibrium condition, which is strongly dependent upon the temperature. The schematics in Figure 3 below show the calculated behavior of Inconel 617 with the nominal NGNP chemistry at 850 and $1000^{\circ} \mathrm{C}$. At $850^{\circ}$ the alloy is in the desired stable region III where a protective oxide is formed, while at $1000{ }^{\circ} \mathrm{C}$ for the same gas chemistry the alloy is predicted to undergo rapid decarburization.

The calculated diagrams for alloy stability in the NGNP atmosphere are based on kinetic reaction constants for both gas-gas reactions and reactions between gases and the surface of the material that are determined from experiment. [3,9] At $850^{\circ} \mathrm{C}$ the kinetic constants are relatively well known and have been validated through extensive comparison between prediction and actual microstructures observed after long term exposure to the impure helium. [9] At higher temperatures the constants are based on extrapolation from known values at $850^{\circ} \mathrm{C}$ and experimental validation is limited or non-existent.

\section{Design and Assembly of a Controlled Chemistry Low Flow Test Loop}

A closed circuit low flow velocity test loop has been designed and assembled at the Idaho National Laboratory (INL). This loop has the ability to expose coupons and mechanical test specimens in controlled impurity atmosphere at high temperature for long periods. Other test systems have been designed where the gas chemistry is controlled by bleeding off a portion of the test atmosphere and refreshing to the desired chemistry with controlled additions of gas. The INL system is designed so that it can operate in this mode, this new system is also designed to with the potential to continuously getter excess impurities and adds necessary trace impurities based on mass spectroscopy measurements in a closed loop system. 
A schematic of the components of the test loop is shown in Figure 4. The schematic shows that the system has a vent system that will only be used in the so called "bleed and feed" mode of operation. The system can be evacuated to a pressure of $10^{-6}$ torr in the specimen chamber using a turbo-molecular pump. All of the tubing for the system is stainless steel and can be heated during evacuation to help remove adsorbed impurities. There is a metal bellows pump in the loop capable of $40 \mathrm{l} / \mathrm{m}$ flow; the total system volume is approximately 20 liters.

The test section consists of concentric quartz tubes inside the furnace section where the cover gas moves down through the annulus and returns up past specimens that will be suspended on a central rod. The hot zone of the retort is approximately $0.75 \mathrm{~m}$ in length and is designed to operate up to $1000^{\circ} \mathrm{C}$. The quartz tubes are sealed to the system using an o-ring assembly that allows tubes to be disassembled to insert and retrieve specimens and to replace quartz tubes as necessary. Details of the retort and fittings are shown in Figure 5. Although provision has been made to water cool the aluminum fittings that hold the o-ring seal assembly for the quartz tubes, experiments with flowing helium up to $1000^{\circ} \mathrm{C}$ have indicated that it will probably not be necessary.

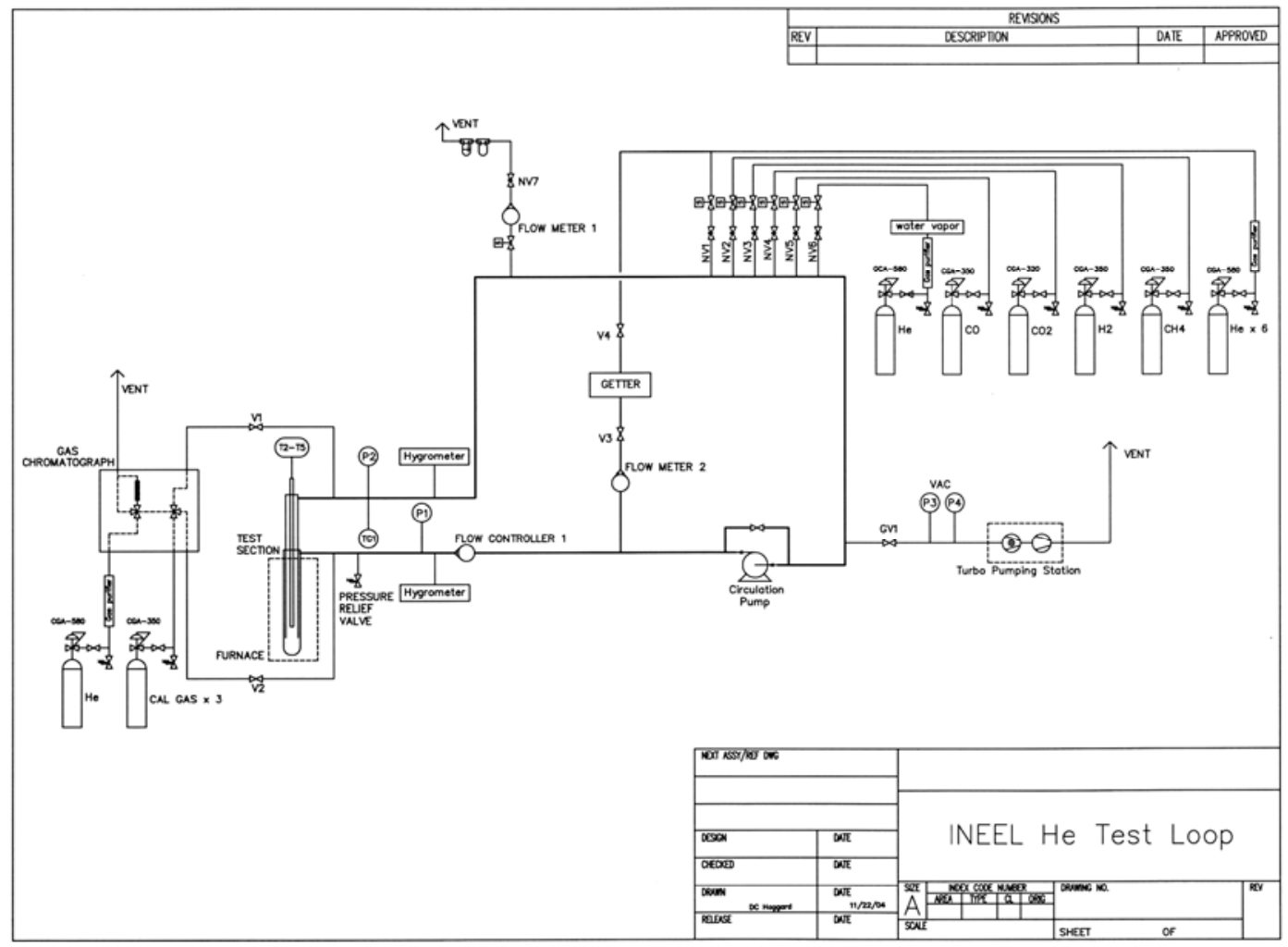

Figure 4. Schematic of the INL low velocity controlled chemistry helium materials test system.

Gas composition is measured going into the retort and upon exit from the hot zone. Water vapor content is measured using solid state hygrometers. The content of the other impurities is measured using a gas chromatograph with a pulsed ionization source. All of the gas compositions will be measured to one part per million or less. As shown in Figure 4, all of the impurities are added to the system as individual gases, rather than premixing gases. A sapphire seated needle valve is used to very precisely control the introduction of each impurity gas into the system. To automate impurity additions, solenoid operated 
rotary valves are used to control the gas that is introduced to the needle valve. A photograph of the needle valves with the attached solenoid operated rotary valves is shown in Figure 6.

As noted in the Background section of this report, the gas composition in the test loop will reach a dynamic steady state condition rather than thermodynamic equilibrium. Although there is a getter shown in Figure 4, until experiments indicate the dynamics of the gas reactions and reactions with specimens it is not possible to accurately predict which impurities if any will be in excess. These experiments will indicate what type of getter(s) will be appropriate for inclusion in the system. There are commercial systems readily available for removal of hydrogen, oxygen and excess carbon and a small volume of the gas will pass through a clean-up system continuously as the gas circulates during testing.

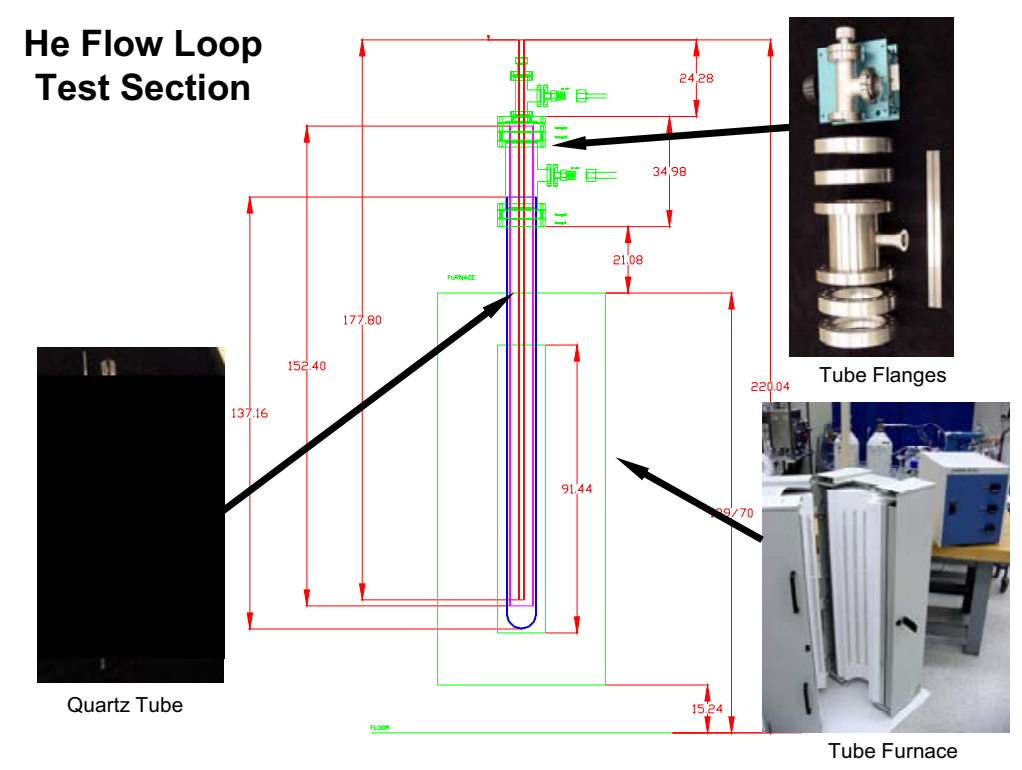

Figure 5. Details of the retort for exposure of test coupons. 


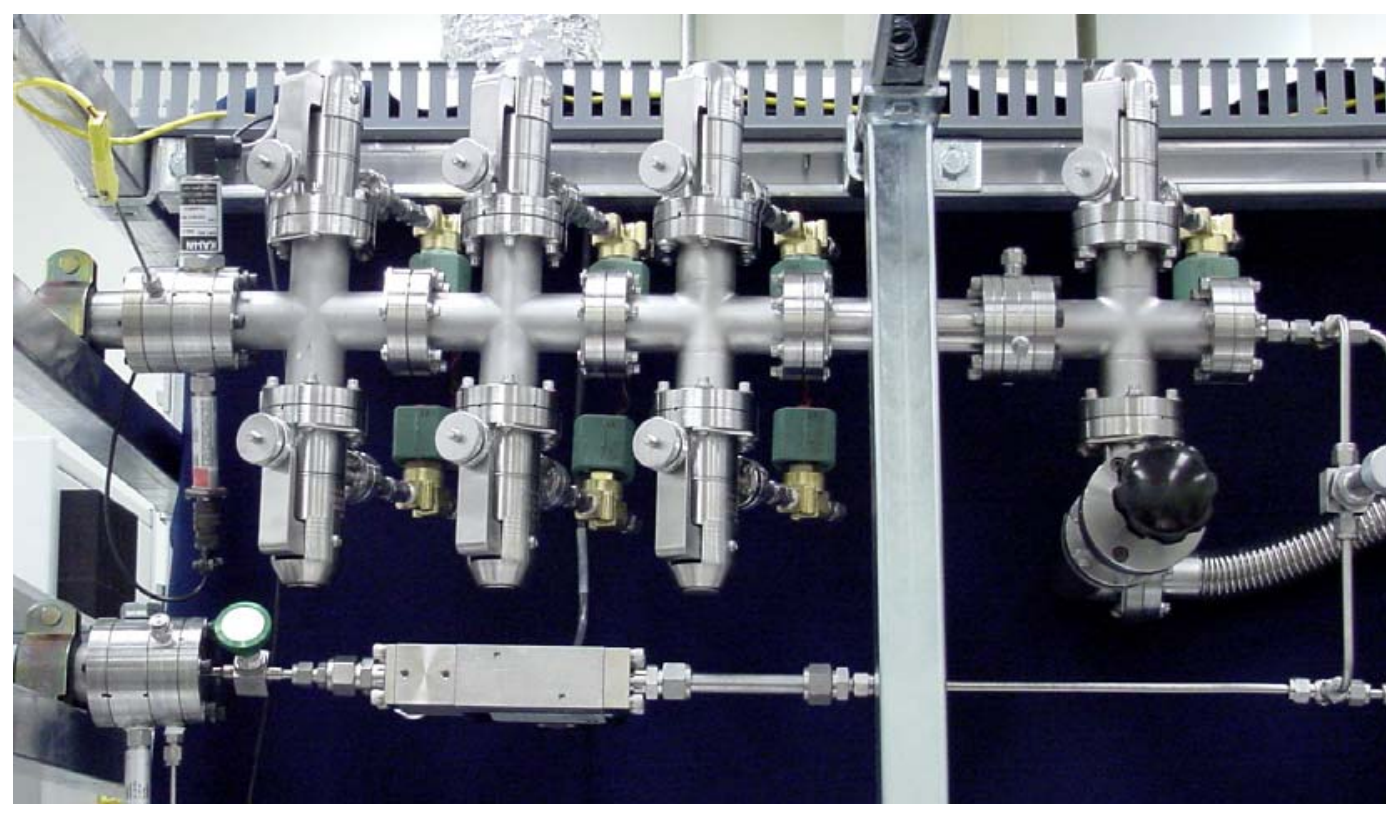

Figure 6. Photograph illustrating the seven sapphire seated needle valves used to introduce very precise amounts of impurity and the attached rotary valves (shown as green in the photo).

\section{Test Plans}

All of the individual components of the test loop, e.g., vacuum system, furnace and retort and helium circulation system, have been tested for proper function during assembly of the test loop. All new projects at INL undergo a safety and environmental compliance review by an Independent Hazard Review Group. The IHR documentation and review for this project was completed and accepted in July.

One important function of this closed loop system is to determine the steady state gas composition as a function of starting gas chemistry. Experiments will be conducted as a function of time and temperature without gettering excess impurities to monitor the evolution of gas chemistry toward the steady state. It is expected for example that initial concentration of $\mathrm{CH}_{4}$ will decline over time as the methane is decomposed at high temperature to $\mathrm{C}$ and $\mathrm{H}_{2}$. After determining the dynamics of gas composition with time at temperature it will be possible to develop appropriate getter systems to remove excess impurities. These experiments will form the basis for design of a much larger high velocity flow loop that will be built in the future to test materials in conditions that more closely simulate the NGNP reactor system where helium flow velocities on the order of 50 to $75 \mathrm{~m} / \mathrm{s}$ are anticipated. 


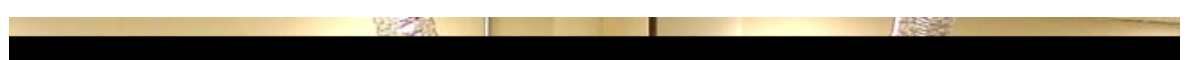

Figure 7. Photograph of the assembled low velocity controlled chemistry test loop. The computer shown controls the measurement of gas chemistry using the mass spectrometer; a second computer that is not shown controls automation of the gas chemistry through operation of the valves shown in Figure 6.

A series of tests will be conducted with Inconel 617 and Alloy 230 with exposures up to 5,000 hours in a range of temperatures from 800 to $1000^{\circ} \mathrm{C}$ under controlled chemistry conditions. These tests will include both coupons for microstructure analysis and mechanical test coupons. The corrosion behavior will be determined on exposed coupons using optical and scanning electron microscopy to characterize the nature and extent of environmental interaction. Transmission electron microscopy may be employed to a very limited extent if determination of the extent or chemistry of phases requires use of this higher resolution tool. A small number of tests will be carried out in the INL test loop for comparison to experiments in Oak Ridge National Laboratory loops with identical conditions to verify that identical results are obtained. More extensive experimental results will be used to validate and refine simulation of behavior in the form of calculated stability diagrams similar to those shown in Figure 3. In this manner the kinetics of environmental interaction with the alloys will be determined.

Note that the diagrams shown in Figure 3 relate only to the formation of chromium oxide. It has been shown previously that there is the potential to form aluminum and titanium oxides under certain oxygen partial pressures. [4,5] Typically the oxides form internally along the grain boundaries. Minor alloying element effects are usually only observed for relatively short times (up to 1,000 hours) because of the limited amount of these elements present in the alloy. Longer term exposures are designed to alloy characterization of alloy behavior subsequent to saturation of the minor element effects.

Mechanical property specimens exposed as companions to microstructure analysis coupons will be used to determine the influence of oxidation or carburization on tensile and creep properties. Properties of Inconel 617 and Alloy 230 under controlled impurity helium will be compared to those determined after aging in air, and to material tested in air and under load. 
Although it is currently anticipated that creep behavior at temperatures above $850^{\circ} \mathrm{C}$ will limit the material selection to either Inconel 617 or Alloy 230, there is the possibility that changes in the design will allow application of more corrosion resistant but lower creep strength alloys like $800 \mathrm{H}$. At a later stage in the test program $800 \mathrm{H}$ will be included; microstructure and properties of this alloy will be determined in a manner similar to those of Inconel 617 and Alloy 230. 


\section{References}

1. D. F. Wilson, Potential Helium Test Environment for Next Generation Nuclear Plant Materials, ORNL/TM - 2005/92, UT-Battelle, LLC, Oak Ridge National Laboratory, 2005.

2. W. J. Quadakkers and H. Schuster, Corrosion of High Temperature Alloys in the Primary Circuit Helium of High Temperature Gas Cooled Reactors - Part I: Theoretical Background, Werkstoffe und Korrosion, Vol. 36, pp. 141-150, 1985.

3. W. J. Quadakkers and H. Schuster, Corrosion of High Temperature Alloys in the Primary Circuit Helium of High Temperature Gas Cooled Reactors - Part II: Experimental Results, Werkstoffe und Korrosion, Vol. 36, pp. 335-347, 1985.

4. W. J. Quadakkers, High Temperature Corrosion in the Service Environments of a Nuclear Process Heat Plant, Materials Science and Engineering, Vol. 87, pp. 107-112.

5. Special Metals Product Bulletin Inconel Alloy 617, Huntington, WV, 2005.

6. Special Metals Product Bulletin Alloy 230, Huntington, WV, 2005.

7. Special Metals Product Bulletin Alloy 800H, Huntington, WV, 2005.

8. Ryohei Tanaka and Tatsuo Kondo, Research and Development on Heat-Resistant Alloys for Nuclear Process Heating in Japan, Materials Technology, Vol. 66, pp. 76-87, 1984.

9. K. Hilpert, H. Gerads and D. F. Lupton, Mass Spectrometric Studies of Alloys Proposed for High Temperature Reactor Systems, Journal of Nuclear Materials, Vol. 80, pp. 126-131, 1979. 